\title{
Metrics, Scribes, and Beowulf: A Response to Neidorf (2017), The Transmission of Beowulf
}

\author{
Nelson Goering ${ }^{1}$ (D) \\ Published online: 1 November 2018 \\ (C) The Author(s) 2018
}

\begin{abstract}
Neidorf (2017), The Transmission of Beowulf, synthesizes a variety of philological approaches to propose a new 'lexemic theory' of Anglo-Saxon scribal behaviour. In this response article, I build on Neidorf's arguments, suggesting ways that his theory may be adapted to account for differences between the two scribes of the Beowulf manuscript, and addressing some of the ways that metrical evidence only more weakly supports, or sometimes directly contradicts, some of Neidorf's specific claims.
\end{abstract}

Keywords Old English $\cdot$ Beowulf $\cdot$ Philology $\cdot$ Metre $\cdot$ Meter

Although in the modern period Beowulf has been the subject of best-selling translations and blockbuster movies, our only source for this poem is a single medieval manuscript, written out around the year 1000, and not treated well in the centuries since. This poem shows clear signs of being a copy from an earlier version of the text, but virtually all details of the poem's history are heavily debated. The controversy about its date is well known, but there is no lack of argument about many further particulars, often centering on practical questions of whether and how specific readings in our text should be emended as errors introduced in the poem's textual history. These errors form the main subject of a recent book by Neidorf (2017), The Transmission of Beowulf, which presents an important and thought-provoking reconsideration of this process of transmission. On the basis of the various mistakes made by the scribes, Neidorf paints a portrait of intelligent and well-meaning late Anglo-Saxon scribes confronted by a bewildering manuscript exemplar produced in a very different cultural and linguistic context. Not only does Neidorf draw out the importance of this gulf between the poet and the copyists, but he also develops a model for the scribes' working methods-what he calls the 'lexemic theory'- to account for precisely why they made the changes (including errors) they did while

Nelson Goering

nelson.goering@ling-phil.ox.ac.uk

1 University of Oxford, Oxford, UK 
reproducing other features of the poem rather faithfully. This paper is intended as a response to Neidorf's book, highlighting some of its more successful conclusions, and providing constructive criticism on two of its major themes: the behaviour of the two final scribes of the Beowulf manuscript, and the role of metre in the editing of Old English poetry today.

\section{Context: Neidorf's Arguments}

Neidorf begins with a programmatic introduction, in which he lays out the scope, premises, and methodology that informs the rest of the study. He accepts the linguistic consensus that Beowulf originally dates to the early eighth century (Ringe and Taylor 2014: 9), giving the poem a textual history of around three centuries before the extant witness was produced. This position will hardly be surprising to anyone familiar with Neidorf's previous work—especially Neidorf (2014)—and this 'early' date of Beowulf is not directly argued for in this book (though understandably much of the argument implicitly reinforces this premise). Neidorf's primary set of data comes from 'errors' in the text, which, he argues, can be detected when they disturb observable regularities in the poem. Some of these regularities are grammatical or semantic, but Neidorf places a particular emphasis on metre as an indicator of textual corruption, noting that '[i]n the wars fought over textual criticism, metre is an impartial weapon: it undermines conservative efforts to defend corrupt readings as effectively as it constrains liberal efforts to bring about specious improvements of sense or style' (2017: 21). This principle is a worthy one, but needs to be employed carefully; I will discuss below cases where metrical evidence is either less strong than Neidorf implies, or indeed actively speaks against some of his claims. The introduction closes with an epistemological discussion of 'probabilistic reasoning', which in all essentials explicitly follows the classic discussion of Fulk (1992: 6-24); Neidorf's presentation is on the whole rather clearer than Fulk's, but also more abbreviated and, partly as a consequence, somewhat less nuanced.

Much of the empirical 'meat' of the book consists of close discussions of specific places where the manuscript of Beowulf appears to require emendation, most of which are collected in chapters 2 and 3. Neidorf generally explains the necessity for each emendation-very often drawing on metrical evidence-before considering what it implies about the differences between the contexts of the scribes who copied Beowulf and the poet who composed it. In the first of these chapters, on 'Language History', the focus is on archaic or dialectal words which a scribe failed to recognize, not being part of their own linguistic or cultural world, and so converted into something more acceptable as a Late West Saxon word. In the following chapter, on 'Cultural Change', Neidorf concentrates on the many proper names which have been corrupted, arguing that these are evidence that later scribes were no longer familiar with the legendary material of Beowulf and altered many names from these traditions which had become obscure in their day. Throughout these chapters Neidorf lays out a typology of scribal changes, distinguishing, for example, trivialization (taking a more marked linguistic form, potentially including an obscure name, and replacing it with something similar and more familiarly Late West Saxon, though 
usually less suited to the context) from interpolation (adding a word, most commonly an unstressed function word, to bring the very terse syntax of traditional verse more in line with Late West Saxon standards).

Most of the material in these two chapters is not new. Neidorf is not trying to add to the large pile of proposed emendations which feature in Old English philology, and focuses only on ones adopted in Fulk et al. (2009) (the majority of these are also found in many other critical editions; compare also Kelly 1982, 1983). The argument lies not in identifying or defending any specific emendation, but collecting transmission errors, classifying them, and drawing conclusions from the patterns that emerge: namely, that there was a sizeable gulf between the scribes and the text they were copying, both linguistically and culturally.

Moving from classification to broader interpretation, Neidorf proposes a theoretical model for the working methods of the late scribes of Beowulf in his fourth chapter. Under this 'lexemic theory', the scribes saw their job in specific terms: they tried to copy the text word by word, modernizing each element into Late West Saxon orthography. They often did not pay attention to the larger sense of any given passage, much less the metre of the poem; even syntactic relations spanning more than the immediate context of two or three words were often overlooked. Although something like this view has been implicitly adopted by many previous scholars, Neidorf seriously advances the discussion of Anglo-Saxon scribal behaviour by arguing his case so explicitly and presenting the evidence for it so clearly. The 'lexemic theory' offers a refreshing alternative from the narrow binary of viewing the scribes either as stupid and lazy or as virtual collaborators in the production of their text. Instead, Neidorf characterizes them as critical (within their cultural limits) and professional, but with very specific aims: to produce sequences of words (and, not infrequently, short phrases) that were acceptably modernized into Late West Saxon orthography. Though there are further complications, which I will return to below, the essentials of this model are convincing, and will surely feature prominently in future studies of Old English scribal behaviour.

Neidorf further contends that this 'lexemic' model is not limited to the scribes of Beowulf, but holds for the normal working methods of late Old English scribes in general. He cites a variety of errors introduced by scribes into each of the three other great poetic codices (MS Junius 11, the Vercelli Book, and the Exeter Book), examines the few examples which exist in both early and late copies, and compares instances of poems or passages surviving in more than one late copy (of which there are some examples, though most poems survive in a single copy only). He finds that there is a role for poetic recomposition in a few cases, but that the standard practice of scribes is accounted for well by the word-by-word modernization model ascribed to the Beowulf copyists.

While the majority of the book focuses on the final stages of textual transmission, in the concluding chapter Neidorf turns his attention to the hypothesized earlier authorial original. He notes that one implication of the 'lexemic theory' is that alterations during transmission ought to drastically obscure certain features, such as the original orthography, while leaving elements such as syntax, metre, and style with only incidental (and often detectable) interference. Neidorf highlights some of these original features, such as the characteristic use of sippan (Bately 1985) and 
Kaluza's law (Bliss 1967: 27-30; Fulk 1992: 160-62; Suzuki 1996a), ${ }^{1}$ noting that they are distributed consistently across the poem. He takes this as evidence for the overall conclusion of the book: that Beowulf, as a poem, is the work of a single author, 'first committed to parchment in Mercia around the year 700' (Neidorf 2017: 160), and that its transmission over some three centuries can be largely explained by copyists taking a 'lexemic' approach to their task.

It is worth emphasizing in this respect that most (though not all) of Neidorf's evidence for single authorship really amounts to an argument that Beowulf is uniformly archaic. The possibility that the poem might have heterogeneous sources assembled into a coherent whole already in the early eight century has recently been raised, or revived, by Drout et al. (2016), and was also apparently the view of Tolkien (2014: 162-163), famous though he is as a proponent of a unified Beowulf. Drout et al. base their argument on statistical distributions of vocabulary in different parts of the text, which, if their methods are accepted, might speak against Neidorf's single-author position; much of Neidorf's evidence could perhaps be reinterpreted as supporting the weaker view that Beowulf is uniformly archaic, not that it is uniformly the work of one single author. On the other hand, there may be no real discrepancy here: that Beowulf may have drawn on earlier sources does not necessarily preclude a general unity of authorship, any more than Shakespeare's clear debt to his sources keeps him from being the author of his plays (an analogy made articulately by Tolkien 2014: 170).

Tolkien's more general views on Beowulf form the subject of the final portion of Neidorf's book, an appendix on 'J.R.R. Tolkien's Beowulf Textual Criticism'. This is largely based on the recently-published lecture notes-mostly originally intended as 'Lectures for the general school, Text, 1-1650' (Tolkien 2014: 131-132)—which were recently edited as an accompaniment to Tolkien's translation of Beowulf. Neidorf reviews a few of Tolkien's specific proposed emendations, including some not otherwise discussed in this book, but mostly he concentrates on Tolkien's general views on the text's history and on the role of the scribes in copying the poem. These views are, as Neidorf notes, largely in agreement with the conclusions of this book: Tolkien saw Beowulf as originally a poem of the 'West Marches' composed during the 'Age of Bede', copied by scribes who 'do not follow the detail of sense' and 'when faced with legendary names, w[ere] plainly at sea', and yet on the whole were conscientious scribes who wrote in a 'careful book-hand' (2014: 315, 345). Neidorf also acknowledges that Tolkien allowed considerably more scope than he himself does for interpolations and poetic reworkings of certain passages during the poem's history, even naming Cynewulf as a possible tamperer at one point. Neidorf correctly notes the improbability that Cynewulf himself should have ever 'touched up'

\footnotetext{
1 The literature on Kaluza's law is too large to really even summarize here adequately; the references provided include some of the most important and influential data-oriented works on the subject. See further chapter 2 of Goering (2016b).
} 
Beowulf, ${ }^{2}$ and observes that large-scale poetic recompositions are difficult to square with the evidence.

\section{'Lexemics', Dialect, and Scribe B of Beowulf}

Taken all together, Neidorf's arguments and conclusions are generally compelling, all the more so because the various individual discussions hang together and reinforce each other remarkably well. He generally makes appropriate effective use of paleographic, linguistic, metrical, and cultural evidence (see below for further discussion of some specifics), and his 'lexemic theory' is a valuable contribution to the study of Old English poetry in general (and could perhaps also be usefully applied to some prose texts as well, especially those under suspicion of having undergone dialect translation). This theory should help move the question of Anglo-Saxon scribal behaviour from whether they had agency to what type of agency they exercised: what their goals and concerns were, and what aspects of a text they might be expected to modify or leave alone.

The 'lexemic theory' is also useful for suggesting new approaches to old problems, with an obvious example being the difference in scribal behaviour between the two copyists of our extant manuscript of Beowulf. Neidorf convincingly argues that both scribes generally worked according to 'lexemic' methods, and offers a wide range of evidence to support this conclusion. But beyond these shared general approaches, there are also differences of detail between the two scribes: every reader of the poem will have noticed that A writes modernized $<$ beopulf $>$ while $\mathrm{B}$ writes the more archaic-looking < biopulf> (which was plausibly the form of the exemplar). It is not simply that B is less prone to modernization, ${ }^{3}$ since B seems to sometimes introduce unetymological pseudo-archaisms (or pseudo-dialecticisms) into the text. This is most obvious with the <io $>$ spellings which are famously more frequent in B's section of Beowulf (but not Judith): examples such as hiold in line $1954 \mathrm{a}$, bìor- at $2635 \mathrm{a}$, or bīodan at $2892 \mathrm{~b}$ are all unetymological.

Though these <io $>$ spellings are clearly not modernizations, a slightly modified form of the 'lexemic theory' might give us a way to explain these forms without the once-popular but implausible appeal to a Kentish layer in the transmission of Beowulf. If the 'lexemic' approach takes the text word by word and converts each lexeme into a spelling acceptable to the scribe, there may be scope for variability in what scribes viewed as acceptable. Scribe A adhered strictly to Late West Saxon

\footnotetext{
2 Tolkien's argument in this regard is particularly surprising, since he had elsewhere cogently observed (on a different but comparable subject) just how imperfect our knowledge of the people of these periods is: "If one considers the throngs of folk in the fair field of the English centuries, busy and studious, learned and lewd, esteemed and infamous, that must have lived without leaving a shred of surviving evidence for their existence, one will hesitate before the most ingenious guesses of the most untiring researchers at the names and identities of the original Canterbury pilgrims" (Tolkien 1929: 116).

3 Though this does seem to be the case. To give just one typical example, B twice allows Mercian eatol 'terrible' to stand, in lines 2074a and 2478a, Saxonizing it only once to atol in 2670a, while A writes atol in nine out of nine instances.
} 
forms, and deviations from this 'standard' either are all in words with no dialectal equivalent (most frequently poetic words), or else are probably incidental holdovers that simply escaped modernization for one reason or another. Scribe B, however, may have allowed more scope for the characteristics of the exemplar to inform the range of what they considered acceptable for their new copy. In line 1954a, when we find the one instance of hiold in the poem, B had only recently taken over the job of copying (having begun in line 1939b), and had just been confronted with diore in 1949a; hiold might be regarded as a hypercorrection, committed by a scribe who allowed the appearance of the manuscript to influence (though not strictly guide) the range of acceptable orthographic variants. This sort of hypercorrection was only sporadic: all later instances of hêeld are spelled as such. Furthermore, 1949a is the only appearance of etymologically correct dīore, and later B writes either $d \bar{y} r e$ (the correct West Saxon form) or déore (a more mechanical orthographic modernization of diore). Modernizations of various sorts are very much the normal state of affairs for B as well as A, but the second scribe apparently gives more weight to the orthography of the exemplar throughout (hence why the name of the poem's hero is modernized without exception by A, but only three times by B). Even A is not necessarily immune from this tendency, though it is far more restricted: both scribes use the abbreviation pôn for bonne when copying Beowulf, but employ it only once each in their other works. These scribal facts are, of course, well known already, but these examples perhaps give a preliminary suggestion of how the 'lexemic theory' might be slightly adapted to allow them to be more consistently understood as the result of the scribes' working methods.

Beyond potential further applications of the 'lexemic theory', the presence of dialect forms in Beowulf raises further questions about the history of text in light of Neidorf's arguments. Neidorf sees the poem as undergoing change not only over the course of three centuries of transmission, but also across dialects, being converted at some point from Mercian into West Saxon. While the questions of date have been much discussed in the literature, the issue of dialect remains understudied, and Neidorf does not really pursue the question of Beowulf's precise original dialect more closely (for examples drawing on earlier literature, see Neidorf 2017: 41, 49, 53, 142f., and the references on 47). Some of his comments do, however, touch on the chronology and development of Mercian dialects, and he at one point raises the possibility that second fronting might have been widespread in Beowulf (Neidorf 2017: 53) ${ }^{4}$; an intriguing idea, but somewhat difficult to accept without more evidence (this sound change is only really widespread in the ninth-century Vespasian Psalter). ${ }^{5}$ Perhaps better grounded is his useful comparison to the early glossaries

\footnotetext{
4 This is in a discussion of lines $3114 \mathrm{~b}-3119$. Neidorf could perhaps have also adduced the potential emendation of weaxan to weosan in this passage, which would serve as a good example of the types of alterations made by the scribes of Beowulf. For this emendation, see Stiles (2004), which is overlooked in Fulk et al. (2009).

5 A similar question of relative chronology potentially comes up with respect to $r$-metathesis: Neidorf implies sometimes that Beowulf postdates this development (e.g. born<*bran; 2017: 52), and other times that it predates it (2017: 56f.). But the latter discussion centres on a discussion of ren/aern, which is from * razn (cf. Gothic razn, Norse rann), and represents a phonological problem extending well beyond questions of $r$-metathesis.
} 
(Neidorf 2017: 41); it is striking how much the Corpus Glossary in particular, heterogeneous though it is, generally gives a very good picture of the sort of language Neidorf envisions for the original of Beowulf. In general, dialect in Beowulf is a topic that could benefit from a closer investigation.

A further explicitly unresolved question concerns the possibility of what any intermediate layers of transmission might have looked like between Neidorf's hypothesized original (in Mercia from around 700) and our extant manuscript some three centuries later. Neidorf simply notes that "[i]n most cases, no decisive method can enable the textual critic to determine whether an error was generated by the final scribes or by antecedent copyists" (2017: 26). Nonetheless, it seems clear that his model works most straightforwardly if we do not imagine too many stages of copying during the late Anglo-Saxon period. Many of the scribal alterations discussed by Neidorf are motivated by late scribes, wrestling not merely with old content (which might have presented itself in more recent mechanical copies), but in some cases with old letter forms or orthography. At least one long gap where no copying occurred is virtually demanded by Neidorf's evidence. The leanest scenario required by the evidence would seem to be that the two scribes of our surviving manuscript were working directly from an eighth-century exemplar (though how many removes such an exemplar might have been from an original seems impossible to even guess at). I should emphasize that Neidorf does not make this argument himself, and indeed it is difficult to demonstrate positively, but it is a natural and plausible inference from the patterns of scribal alteration discussed in his book.

\section{Metrics and Probability: D* Verses and i-Stem Genitive Plurals}

Metrics plays a central role in Neidorf's book, and metrical anomalies in particular are often cited as strong evidence in detecting errors of transmission. Often his use of metrical evidence is well-founded and sound, but there are a number of specific points where his methodology or evidence require correction or qualification. As he himself notes, metre is probably best employed as part of wider 'probabilistic reasoning', according to which the accumulation of evidence means that "[e]ven without definitive proof, the probability of many text-critical hypotheses can approximate virtual certainty" (2017: 23). This is in general a fair enough point, but Neidorf sometimes overstates the level of probability for particular issues. ${ }^{6}$ One recurrent example of this involves his assertion that off-verse D* verses "are restricted to the on-verse and require double alliteration" (2017: 18; cf. pp. 40, 54, 55, 66, 71, 125 , 156f.).

D* verses are those like mōere mearcstapa (103a), which have a rhythm that can be notated as $/ \times / \backslash \times$, where $/$ represents a full stress, $\backslash$ a secondary stress, and $\times$ a

\footnotetext{
${ }^{6}$ A simple non-metrical example of this is the discussion of weorc as a trivialization of warc 'pain'. In two of the cases discussed, Neidorf's interpretation (2017: 48f., following Fulk 2004) makes good sense, but in $1638 \mathrm{~b}$ either weorc 'labour' or *wrac 'painful effort' would make for equally satisfactory readings.
} 
'dip' or unstressed syllable. ${ }^{7}$ They are somewhat longer and heavier than typical Old English verses (under the widely-used positional theories, they stand out for having five positions rather than the usual four), and have received a good deal of comment from metricists. In his characterization of $\mathrm{D}^{*}$ verses, Neidorf is following the dubious example of Bliss (1967: 57-58), who had gone to decidedly improbable lengths to make all D* verses in Beowulf conform to his rule that they have double alliteration (and so appear in the on-verse, since double alliteration is prohibited in the offverse). Bliss noted a number of apparent exceptions to this rule, including:

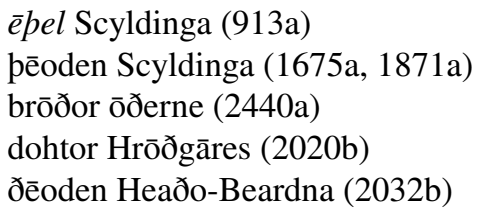

Bliss simply says that in these cases the second syllable should be underdotted, usually a mark that an unetymological syllable is to be ignored in scansion. Although Fulk (1992: 88-90) is aware that all these examples involve etymologically real second syllables (cf. Norse óðal, pjóðann, bróðír, dóttír), he nonetheless accepts them as 'analogical' examples of a disyllable being treated as a monosyllable, and Fulk et al. (2009) accordingly print all of these examples with Bliss's underdot.

It is unfortunate that Bliss's claim should be accepted so readily by Fulk and Neidorf, since it is not a well-motivated solution. Fulk himself is at pains to argue that 'analogical' non-parasiting is extremely rare and unusual, but he does not observe that he limits it to only one specific metrical context in Beowulf: what on the surface look like the second positions of $\mathrm{D}^{*}$ verses. It does not seem plausible that of all the times peoden is found in Beowulf, the only time it should be treated (against etymology) as a monosyllable is in this one particular verse context. If this were a license the poet genuinely allowed, we should also expect verses such as:

${ }^{x}$ Weder-Gēata pēodẹn (cf. 1492b, etc.)

A better understanding of $\mathrm{D}^{*}$ verses instead comes from the observation that the second element of this type of verse usually contains a poetic compound or a wordgroup (Cable 1991: 143). Most $\mathrm{D}^{*}$ verses then require double alliteration (and so are placed in the on-verse) because of Krackow's rule, which holds that such elements must alliterate. One thing that most of Bliss's singly-alliterating $\mathrm{D}^{*}$ verses share is that they do not contain such a mandatorily-alliterating second element: Krackow's rule does not apply to ethnonyms such as Scyldinga or Heaðo-Beardna (Russom 1987: 97), to personal names such as Hröðgäres or Aschere (in 1323b, potentially another singly-alliterating $\mathrm{D}^{*}$ verse), to common words such as őerne '[the] other'

\footnotetext{
7 A standard introduction to Old English metrics is Terasawa (2011). Some of the specifics of metrical theory remain debated, but essential recent works on the underpinnings of the system include Russom (1987), Cable (1991), Hutcheson (1995), Suzuki (1996b), and Yakovlev (2008). Most contemporary work is founded in one way or another on the classic Sievers (1893). Though long a standard work in the field, Bliss (1967) should only be used with caution (Pascual 2016).
} 
or owihte 'at all' (in 2432b, not included in Bliss's list), or to verbs such as the frequent mapelode (sometimes dismissed as a metrical licence, as in Bliss 1962: 23 or Fulk et al. 2009: 331, as if poets could contrive of no standard speech formula that did not regularly violate metrical constraints). Since the authenticity of these verses is otherwise not in doubt-1675a and 1871a seem to be a repeated formula, closely echoed in 913a and 2032b (this last further supported by Widsith 32b)—it seems clear that there is no absolute rule for $\mathrm{D}^{*}$ to have double alliteration. Rather, there is a strong tendency for $\mathrm{D}^{*}$ verses to have poetic compounds or word-groups as their second elements, and it is the application of Krackow's rule to such elements that accounts for the high frequency of double alliteration in the type. ${ }^{8}$

This tendency for $\mathrm{D}^{*}$ verses to end in 'Krackow elements' can certainly be invoked in a truly probabilistic way-in conjunction with other factors-to support emendations. A good example is the interchange of nēosan versus nēosian (Neidorf 2017: 55), where the fact that the latter variant produces unusual off-verse $D^{*}$ patterns reinforces the evidence of dialect and orthographic variation within the manuscript. Metre does support Neidorf's defense of nēosan as uniformly the original form-it is just that the metrical criterion alone is not by itself as decisive as Neidorf implies. Metrical considerations similarly reinforce our doubts about scribally-transmitted inflected infinitives (2017: 36), unsyncopated medial syllables (54), or the longer form of the preverb of ymbesittendra in 2734a (67), where we have independent evidence about the linguistic variations in question.

Nevertheless, we should not rely too heavily on the lack of alliteration in a $\mathrm{D}^{*}$ verse alone, especially when other evidence is less straightforward. For example, Neidorf (2017: 40) endorses Daniel Donoghue's emendation of 2717b to:

seohan enta geweorc

This is of course a notoriously odd verse, containing an off-verse of type $\mathrm{Db}^{*}$ with single alliteration on a finite verb, and this emendation would indeed regularize it nicely. On the other hand, Neidorf takes no notice of the closely parallel Ruin 2b:

brosnað enta geweorc

This verse is parallel in every way to $2717 \mathrm{~b}$ : it would seem to scan as $/ \times / \times 1$, a $\mathrm{Db}^{*}$ pattern which is unusual in the off-verse (and somewhat rarer than $\mathrm{Da}^{*}$ across the board), and its single alliteration is carried by the finite verb brosnað rather than the phrase enta geweorc which we might expect to alliterate both by general considerations of precedence and by Krackow's rule (though see Russom 1987: 91-92). Ruin $2 \mathrm{~b}$ cannot be emended in any way comparable to Beo $2717 \mathrm{~b}$, and might suggest that both are validly, if perhaps marginally, metrical. It is not that Neidorf's metrical argument is invalid or carries no probabilistic force, but there are factors pointing in various directions: whatever option we choose in this particular case will fall

\footnotetext{
${ }^{8}$ Even within singly-alliterating $D^{*}$ verses, there seems to be a preference for placement in the on-verse, though otherwise good examples like 2020b and 2032b suggest that occurrence in the off-verse is at least marginally metrical (on the notion of gradient metricality, which is important for the proper application of metrical rules in textual criticism, see Russom 1987: 31-32).
} 
short of the ideal of 'virtual certainty'. This is a probabilistic grey-area that anyone employing probabilistic reasoning has to live with on occasion.

Similar uncertainties face an emendation that Neidorf refers to repeatedly: the substitution of Bēow for Bēowulf in lines 18a and 53b (2017: 18, 73ff., etc.). Neidorf's arguments against the transmitted name Bēowulf are both metrical (53b as written is an example type $\mathrm{D}^{*}$ in the off-verse with single alliteration) and interpretative (based on a comparison with the genealogical evidence for Scyld Scēfing's family tree). Emendation of some sort seems clearly justified, but it is not self-evident that $B \bar{e} o w$ is the proper form to substitute, rather than Béewi, found in the same genealogies as $B \bar{e} a w / B \bar{e} o$ (both as such, and in corrupted form as Bedwig, and possibly Latinized Beowius). Historical phonology does not help much, beyond suggesting that if the monosyllabic form is correct, it should be $B \bar{e} o$ (for early Old English

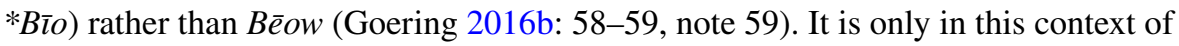
uncertainty that the metrical evidence really begins to weigh, since assuming Bēowi would result in a $\mathrm{D}^{*}$ off-verse:

\section{Bēowi Scyldinga}

Here we have a very good case against the manuscript reading Bēowulf, and a

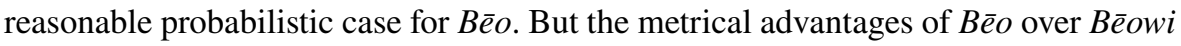
are, while real, perhaps not so great as to 'approximate virtual certainty' about the precise form to be restored.

If the scansion of $\mathrm{D}^{*}$ verses carries somewhat less probabilistic weight than Neidorf implies, there are other examples where metrical evidence in fact speaks quite strongly against some of his proposed restorations-though of course on another level this exemplifies Neidorf's methodological point that metre is indeed an 'impartial weapon' (2017: 21) in textual criticism. The clearest example of this concerns the archaic long genitive $i$-stem plurals Deni(ge $) a$ and winia, which occur in Beowulf alongside younger Dena and wina. Neidorf argues that the poet originally employed the long forms only, and that their current distribution, with the trisyllables usually altered to Dena, wina in cases where the long form was not metrically required, ${ }^{9}$ is due to the interference of a later scribe (2017: 38). Neidorf attributes this intervention specifically to an earlier copyist, noting that the final scribes of our manuscript usually pay no heed to the metre at all. If accepted, this would provide some interesting evidence about an intermediate layer of Beowulf's history, one in which metrically-aware scribes played a more active role in reshaping the text.

However, this distribution of short and long $i$-stem plurals is almost certainly authorial. Pace Neidorf, the restoration of Denia for Dena would very often disturb the metre, producing verses such as:

Hwæt wē Gārdenia (1a)

brego Beorhtdenia (609a)

\footnotetext{
9 Except for Denigea in Beo 1670a, where the long form is not metrically necessary.
} 
Neidorf assumes that the sequence -deni- would be resolved, the light ${ }^{10}$ syllable $d e$ - combining with the following syllable $n i$ - to count as a single metrical position. Resolution is a crucial principle in Old English metrics, but there are also restrictions on where it can apply. In this case, it is notable that the poet strongly avoids resolution in such positions (the penultimate position of verse-final compounds), probably for good metrical-phonological reasons (Goering 2016b: 142-143, 146-151), and each of these verses has just one linguistically-dubious parallel (1946a for compound-final type C, and $2921 \mathrm{~b}$ for D). ${ }^{11}$ It seems more plausible to assume that the poet determined the general distribution of shorter and longer $i$-stem genitives, presumably employing the latter as an archaic metrical convenience.

There are a number of further smaller points worth noting where the metrical or broader philological evidence is weaker or more complicated than Neidorf implies - this is inevitable in a study of this breadth, which draws on a wide range of various types of evidence, but they still deserve a brief mention. To start with purely metrical matters, resolution is not dependent on or unique to the four-position theory of metre (Neidorf 2017: 4); it is also a core part of its chief theoretical competitor, the word-foot theory (Russom 1987: 11f.). Neidorf at one point claims that the metre confirms the authenticity of the element -peo over -peow (2017: 45),

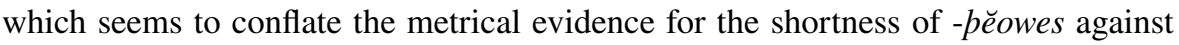
-péewes with the purely linguistic evidence concerning the restoration of $-w$ in the nominative/accusative singular. He also objects to the form sibbegedriht by appealing to Terasawa's rule (2017: 64f.), but this rule prohibits only resolved sequences as the second elements of a compound following a trochaic initial element, and gedriht is not a resolvable sequence (Terasawa 1994: 8-15); this form may in fact be an archaic feature rather than an innovation. Neidorf presents the form modceare as resolving in accordance with Kaluza's law (2017: 141 and 172 n. 14), but early shortening of Proto-Germanic $*_{-} \bar{o}^{n}$ is linguistically unlikely and not supported by a broader view of the metrical evidence (Goering 2016b: 98-105): verses 1778a and $3149 \mathrm{a}$ are probably among perhaps four genuine exceptions to the law in the poem. ${ }^{12}$ He also objects to the idea of Hrēðmanna and Hrēðsecgum as ethnonyms on the grounds that they violate Krackow's law (2017: 168), but this law does not apply

\footnotetext{
${ }^{10}$ A 'light' syllable is one that contains only a short vowel (or short diphthong), while a 'heavy' syllable contains either a long vowel (or long diphthong) or one or more consonants in the syllable coda. Old English words are divided so that a single consonant between vowels belongs to the onset of the second syllable (de-na), while clusters are divided between syllables (el-len, en-de). In these examples, de-is a light syllable, while $e l$ - and $e n$ - are heavy (the $r \bar{a}$ - of räde and the prēa- of prêatum are also heavy by virtue of their long vowels). Heavy syllables may never resolve under any circumstances.

11 A few Dena verses could indeed be restored to Denia and remain at least marginally metrical. In 242a, $253 \mathrm{~b}$, and 668a restoration to Denia would give a type paralleled in 2096b and 2796b; this restoration would still result in a highly unusual pattern, but they are potentially marginally more metrical than those verses in which -dena is subordinated as the second element of a compound. Only verses 498b, 657a, and 2035a could be restored to Denia without metrical complication.

12 With regard to Kaluza's law, the form *wracôz (Neidorf 2017: 5) should be corrected to *wrakōz (Sievers 1893: 275; Stiles 1988: 139, n. 17; Ringe 2006: 279; Ringe and Taylor 2014: 59); the ending remains long in early Old English *wrake because the vowel was not final at the time of Northwest Germanic final shortening, not because the ending was previously trimoric (Goering 2016a: 181-185). In fairness to Neidorf, many standard handbooks are incorrect or misrepresentative on this point.
} 
to ethnonyms (Russom 1987: 97). The alliteration may indeed provide a suggestion that manna and secgum occupy lifts, but the metre does not speak against seeing tribal names in these verses.

\section{Future Work}

The metrical points of the previous section highlight how difficult it can be to combine evidence from such varied sources. Despite the long history of fields such as dialectology, historical linguistics, scribal studies, palaeography, cultural history, and metrics itself, these remain active and dynamic fields, and each is often highly technical in its own right. This should not be taken as a criticism of the kind of synthesis attempted here, but rather as a promise of how much more these fields have to offer, both in their own rights, and in conversation with each other in the context of Old English studies as a whole.

The promise of much future work is also offered by the specifics of Neidorf's study, and especially his 'lexemic theory'. This is not only a useful distillation, defence, and elaboration of a view of scribal behaviour that has so far remained implicit (and so sometimes inconsistent) in philological work, but also a useful framework to be adapted and extended in the future. I have tried to suggest a few ways that we might develop this theory further even just with regard to Beowulf, and there is surely much more to be done on other poetic, and even prose texts. This book represents not only an important contribution in its own right, but the promise of continued conversation and study to come.

Open Access This article is distributed under the terms of the Creative Commons Attribution 4.0 International License (http://creativecommons.org/licenses/by/4.0/), which permits unrestricted use, distribution, and reproduction in any medium, provided you give appropriate credit to the original author(s) and the source, provide a link to the Creative Commons license, and indicate if changes were made.

\section{References}

Bately, J. (1985). Linguistic evidence as a guide to the authorship of Old English verse: A reappraisal, with special reference to Beowulf. In M. Lapidge \& H. Gneuss (Eds.), Learning and literature in Anglo-Saxon England: Studies presented to Peter Clemoes on the occasion of his sixty-fifth birthday (pp. 409-431). Cambridge: Cambridge University Press.

Bliss, A. J. (1962). An introduction to Old English metre. Oxford: Blackwell.

Bliss, A. J. (1967). The metre of Beowulf. Oxford: Blackwell.

Cable, T. (1991). The English alliterative tradition. Philadelphia: University of Pennsylvania Press.

Drout, M. D. C., Kisor, Y., Smith, L., Dennett, A., \& Piirainen, N. (2016). Beowulf unlocked: New evidence from lexomic analysis. Basingstoke: Palgrave Macmillan.

Fulk, R. D. (1992). A history of Old English meter. Philadelphia: University of Pennsylvania Press.

Fulk, R. D. (2004). Old English weorc: Where does it hurt? South of the Thames. ANQ, 17(2), 7-12.

Fulk, R. D., Bjork, R. E., \& Niles, J. D. (Eds.). (2009). Klaeber's Beowulf and the fight at Finnsburg (4th ed.) corrected reprint. Toronto: University of Toronto Press. 
Goering, N. (2016a). Early Old English foot structure. Transactions of the Philological Society, 114(2), $171-197$.

Goering, N. (2016b). The linguistic elements of Old Germanic metre: Phonology, metrical theory, and the development of alliterative verse. DPhil dissertation, University of Oxford.

Hutcheson, B. R. (1995). Old English poetic metre. Cambridge: D. S. Brewer.

Kelly, B. (1982). The formative stages of Beowulf textual scholarship: Part I. Anglo-Saxon England, 11, $247-274$.

Kelly, B. (1983). The formative stages of Beowulf textual scholarship: Part II. Anglo-Saxon England, 12, 239-275.

Neidorf, L. (2017). The transmission of Beowulf: Language, culture, and scribal behavior. Ithaca: Cornell University Press.

Pascual, R. J. (2016). Sievers, Bliss, Fulk, and Old English metrical theory. In L. Neidorf, R. J. Pascual, \& T. Shippey (Eds.), Old English philology: Studies in honour of R.D. Fulk (pp. 17-33). Cambridge: D. S. Brewer.

Ringe, D. (2006). From Proto-Indo-European to Proto-Germanic. A linguistic history of English (Vol. 1). Oxford: Oxford University Press.

Ringe, D., \& Taylor, A. (2014). From Proto-Germanic to Old English. A linguistic history of English (Vol. 2). Oxford: Oxford University Press.

Russom, G. (1987). Old English meter and linguistics theory. Cambridge: Cambridge University Press.

Sievers, E. (1893). Editorial footnote to van Helten, 'Grammatisches'. Beiträge zur Geschichte der deutschen Sprache und Literatur, 17, 274-275.

Stiles, P. V. (1988). The Gothic nominative singular Brōpar 'brother' and the reflexes of Indo-European long vowels in the final syllables of Germanic polysyllables. Transactions of the Philological Society, 86(2), 115-143.

Stiles, P. V. (2004). Consumer issues: Beowulf 3115a and Germanic 'Bison'. In J. H. W. Penney (Ed.), Perspectives on Indo-European: Studies in honour of Anna Morpurgo Davies (pp. 461-473). Oxford: Oxford University Press.

Suzuki, S. (1996a). Preference conditions for resolution in the meter of Beowulf: Kaluza's law reconsidered. Modern Philology, 93(3), 281-306.

Suzuki, S. (1996b). The metrical organization of Beowulf: Prototype and isomorphism. Berlin: Mouton de Gruyter.

Terasawa, J. (1994). Nominal compounds in Old English: A metrical approach. Copenhagen: Rosenkilde / Bagger.

Terasawa, J. (2011). Old English metre: An introduction. Toronto: University of Toronto Press.

Tolkien, J. R. R. (1929). Ancrene Wisse and Hali Meiðhad. Essays and Studies, 14, 104-126.

Tolkien, J. R. R. (2014). Beowulf: A translation and commentary, C. Tolkien (Ed.). London: HarperCollins.

Yakovlev, N. (2008). The development of alliterative metre from Old to Middle English. DPhil diss.: University of Oxford. 